\title{
Avaliação in vitro do potencial antimicrobiano de Morinda citrofolia - Noni e do óleo de Melaleuca em casos de Candida albicans
}

\author{
In vitro evaluation of antimicrobial potential of Morinda citrofolia - Noni \\ and Melaleuca oil in Candida albicans cases
}

\author{
1 Gabrielle Cristina Figueiredo da Silva gabriellefigueiredo9@gmail.com \\ 2 Leonardo de Paula Pereira \\ 2 Caio Wilker Teixeira \\ 2 Natielle Cerceau Marteleto \\ ${ }^{3}$ Marisa Cristina da Fonseca Casteluber
}

\begin{abstract}
Graduada em Ciências Biológicas pela UEMG - Ibirité e Mestranda em Imunologia na Universidade Federal de Ouro Preto.
2 Discente do curso de Ciências Biológicas da Universidade do Estado de Minas Gerais (Unidade de Ibirité), membro (a) do Laboratório de Microbiologia Aplicada (LAMAP). Universidade do Estado de Minas Gerais. Departamento de Ciências Biológicas.

3 Professora de Mcirobiologia Adjunta do Departamento de Ciências Biológicas da Universidade do Estado de Minas Gerais. Coordenadora do Laboratório de Microbiologia Aplicada. Universidade do Estado de Minas Gerais- Departamento de Ciências Biológicas.
\end{abstract}

\section{RESUMO}

A Candida albicans é uma levedura considerada oportunista e responsável por causar infecções, quando há uma baixa no sistema imunológico do indivíduo. Com o aumento do número de micro-organismos multirresistentes aos fármacos convencionais, é importante o estudo da composição de determinadas plantas para a descoberta de tratamentos naturais alternativos. 0 objetivo deste trabalho foi avaliar o potencial antimicrobiano do extrato de Morinda citrofolia e do óleo de Melaleuca em casos de Candida albicans. A preparação do extrato de $M$. citrofolia foi obtida através do fruto maduro descascado, despolpado e sem sementes, submetidos à filtração por peneira seguida de centrifugação. Já o óleo essencial de melaleuca, foi diluído (10\%) em óleo vegetal. Uma cepa ATCC® 10231 de Candida albicans foi inoculada em ágar sabouraud dextrosado, utilizando-se a técnica de espalhamento e mantida em estufa por um período de 7 a 14 dias em temperatura de $28-30^{\circ} \mathrm{C}$. 0 óleo essencial de melaleuca foi o que apresentou o maior halo de inibição, seguido do Fluconazol (usado como controle positivo), que apresentou halos menores ou iguais ao do óleo de melaleuca, quando comparado ao controle negativo e ao Noni $(p \leq 0,05)$.

\section{Palavras-chave}

Fitoterápicos. Candidíase. Óleos essenciais. Remédio alternativo.

\section{Como você deve citar?}

SILVA, Gabrielle Cristina Figueiredo da et al. Avaliação in vitro do potencial antimicrobiano de Morinda citrofolia - Noni e do óleo de Melaleuca em casos de Candida albicans. Cadernos UniFOA, Volta Redonda, n. 45 , p. 147- 155, abril. 2021.

\begin{abstract}
Candida albicans is an opportunistic yeast responsible for causing infection when the individual's immune system is weakened. With the increase in the number of resistant microorganisms to the conventional drugs, it is important to study the composition of certain plants to discovery alternative natural treatments. The objective of this work was to evaluate the antimicrobial potential of Morinda citrofolia extract and Melaleuca oil on Candida albicans. The preparation of the extract of M. citrofolia was obtained through the peeled, pulped, and seedless rape fruit, submitted to filtration through a sieve followed by centrifugation. Melaleuca essential oil was diluted (10\%) in vegetable oil. An ATCC $₫ 10231$ strain of Candida albicans was inoculated on dextrose sabouraud agar using the spreading technique and kept in an oven for 7 to 14 days at a temperature of 28-30 ${ }^{\circ} \mathrm{C}$. Melaleuca essential oil showed the highest inhibition halo, followed by Fluconazole (used as a positive control) which showed halos less than or equal to melaleuca oil when compared to negative control and to Noni $(p \leq 0.05)$.
\end{abstract}

\section{Keywords}

Phitotherapics. Candidiasis. Essential oils. Alternative remedy. 


\section{INTRODUÇÃO}

As plantas medicinais são utilizadas como tratamento para diversas doenças há centenas de anos. As antigas civilizações, verificando a eficácia de algumas espécies de plantas, as cultivavam para que suas gerações vindouras pudessem utilizá-las (FEIJÓ et al., 2012).

De acordo com Oliveira (2011), a procura por medicamentos naturais tem crescido, não somente pelo alto custo dos medicamentos convencionais industrializados, mas também pelo fato de muitos micro-organismos terem se mostrado, em alguns casos, resistentes aos medicamentos convencionais, impulsionando, assim, a busca por tratamentos naturais alternativos.

A utilização de plantas medicinais em todo o mundo alcançou valores econômicos significativos nos últimos anos, o que justifica muito a procura atual por novos princípios bioativos (SCHULZ, 2001). Segundo Duarte (2006), o número de publicações indexadas sobre extrato de plantas como potencial antimicrobiano vem aumentando durante os anos, sendo que, Brasil, foi responsável por cerca de quase $50 \%$ das publicações na área, podendo ser justificado pela grande diversidade de plantas e também pelo potencial de descobertas de outras ainda não descritas (SANTOS et al., 2019).

Dentre as plantas utilizadas para o tratamento de enfermidades, destaca-se a Morinda citrifolia, popularmente conhecida como "Noni". Trata-se de uma planta originária do Sudoeste da Austrália e Ásia, sendo distribuída em toda a região do Pacífico, principalmente nas Ilhas da Polinésia Francesa, e é abundante no Taiti (NELSON; ELEVITCH, 2006). Essa planta vem sendo cultivada no Brasil, principalmente na região litorânea e utilizada para o tratamento de enfermidades e, em alguns casos, o fruto tem sido consumido na forma de suco.

M. citrifolia é associada a diversas propriedades terapêuticas, e diversos estudos foram executados sobre os benefícios dessa planta, revelando e comprovando algumas de suas atividades biológicas como: antibacteriana, anti-inflamatória, analgésica, hipotensiva. Também foram demonstradas propriedades que apontavam melhorias na resposta imune em seres humanos (PAWLUS; KINGHORN, 2007). Apesar de muitas pesquisas com M. citrifolia, observa-se que há poucos relatos documentados sobre os efeitos antifúngicos do Noni contra o fungo Candida albicans (BARANI et al., 2014).

De acordo com Cruz (2013), a forma mais consumida da M. citrifolia é o suco da fruta, podendo ser encontrado também, no comércio, o extrato seco da fruta em cápsulas. Eles ainda afirmaram que o suco do Noni apresentou propriedades antioxidantes e anti-inflamatórias in vitro. Além disso, compostos, como L-asperilosideo, escopoletina e alizarina, foram relatados como responsáveis pelos efeitos antibióticos, antitumorais, antioxidantes e anti-inflamatórios do Noni.

Estudos comprovaram também que o extrato de folhas da Morinda citrifolia atuou como larvicida contra o Aedes aegypti, o Culex quinquefasciatus e o Anopheles stephensi. No mesmo estudo, também foi observada a capacidade do Noni em estimular a formação óssea no tecido periodontal humano, que é explicada pela existência de alguns princípios ativos em suas folhas, como a vitamina $\mathrm{C}$, os triterpenos e flavanoides (BOONANANTANASARN et al., 2012).

Atualmente, o uso popular do Noni é muito amplo, sendo utilizado tradicionalmente em casos de diabetes, leucorreia, febre, asma, depressão, artrite, hipertensão, doenças cardiovasculares, além de irregularidades menstruais, distúrbios gastrointestinais e até mesmo câncer (LIMA, 2008).

Observa-se o crescente número de estudos sobre o Noni e suas composições químicas e biológicas para fins terapêuticos. Devido a isso, é necessário explorar melhor os mecanismos de atividades 
farmacológicas e pesquisas que avaliem a eficácia do Noni, principalmente como fungicida, pois apesar de ser muito utilizado no meio popular como antifúngico, há poucos estudos documentados a respeito do seu potencial inibidor da C. albicans (GUPTA; SANTANA, 2012).

Outra planta muito utilizada para fins medicinais em tratamentos de enfermidades provocadas por fungos e bactérias é a Melaleuca alternifolia, da família Myrtaceae, também conhecida como "árvore do chá". É oriunda da Austrália e de suas folhas e ramos são extraídos os óleos essenciais de melaleuca (MOREIRA, 2010).

Estudos farmacológicos com o óleo da Melaleuca demonstraram que ele contém propriedades cicatrizantes, antissépticas, bactericidas e expectorantes. De acordo com Corazza (2004), popularmente, o óleo é aplicado em tratamentos de cortes, ferimentos, arranhões, infecções cutâneas fúngicas e bacterianas.

O óleo de melaleuca contém, aproximadamente, 100 componentes, dos quais terpinen- 4-ol, 1,8-cineol, a-terpineol, terpinoleno e a- e $y$-terpineno englobam cerca de $90 \%$ da constituição do óleo (MARTINS, et al., 2010).

O óleo de melaleuca possui comprovada ação antimicrobiana contra bactérias Gram-positivas e Gram-negativas, e alguns vírus, além de forte desempenho como repelente contra pulgas, mosquitos e piolhos (SIMÕES et al., 2002). Ainda possui propriedades antissépticas, cicatrizantes e expectorantes. Atualmente, devido a evidências de uso popular, o óleo é utilizado em tratamentos de ferimentos, arranhões, cortes e ferimentos por infecções fúngicas e bacterianas (CORAZZA, 2004).

Observa-se que estudos feitos com a composição química e a atividade antimicrobiana do óleo de M. alternifolia cultivada no Brasil apontam que ele dispõe das mesmas características quantitativas e qualitativas do óleo australiano (SILVA, 2001).

A Candida albicans é uma levedura comensal encontrada facilmente na mucosa bucal, no trato gastrointestinal, urogenital e na pele do ser humano desde o nascimento. 0 gênero Candida faz parte da microbiota normal dos indivíduos saudáveis, no entanto, quando há modificações nessa microbiota ou perturbações do sistema imune do hospedeiro, as espécies desse gênero podem manifestar-se agressivamente, tornando-se patogênicas (MELO, 2016). Estudos realizados comprovam que cerca de $20 \%$ a $50 \%$ da população possui Candida na cavidade bucal e a espécie $C$. albicans é responsável por $60-90 \%$ dos isolamentos (SANTANA, 2013).

As manifestações clínicas da espécie são diversificadas, mas a forma mais comum em humanos é a Candidíase, que não se manifesta em hospedeiros em bom estado de saúde. Para a manifestação, é necessário que o sistema imunológico do indivíduo esteja debilitado, o que facilita o crescimento do fungo (MELO, 2016). Estudos também comprovaram que a Candidíase afeta mais de um terço dos indivíduos infectados pelo vírus HIV, que podem apresentar qualquer uma das formas da doença (NETO et al., 2005).

Segundo Santana (2013), os aspectos microbiológicos da C. albicans é caracterizado pela morfologia colonial úmida, cremosa e de odor específico, tendo aspecto liso ou rugoso e coloração branco amarelada. $\mathrm{O}$ crescimento da espécie é realizado em temperaturas que variam entre $20^{\circ} \mathrm{C}$ a $38^{\circ} \mathrm{C}$. $\mathrm{O} \mathrm{pH}$ ácido também beneficia na sua proliferação, sendo que a faixa ideal de pH varia de 2,5 até 7,5.

Santana (2013) também discorre que a Candida expressa uma série de estratégias específicas para se estabelecer, colonizar, causar a doença e superar as defesas de hospedeiros suscetíveis. Em vista disso, a Candida albicans tem se mostrado resistente a medicamentos convencionais e, por isso, várias alternativas estão sendo pesquisadas, entre elas, os tratamentos naturais que apresentam ação antifúngica eficiente. 
Em vista das funções antimicrobianas comprovadas por meio de estudos sobre o óleo de melaleuca e do Noni, este estudo almejou testar in vitro dois extratos obtidos (Noni e óleo de melaleuca), como inibidores farmacológicos naturais de Candida albicans e verificar se esses extratos possuem potenciais de inibição de crescimento do fungo. No Brasil, atualmente, as infecções fúngicas são largamente tratadas com o Fluconazol, às vezes de forma indiscriminada, prática que pode induzir alguns efeitos colaterais, culminando, algumas vezes, na desistência do paciente em continuar o tratamento contra o fungo, acarretando assim, nas recidivas da infecção por $C$. albicans.

\section{METODOLOGIA}

\subsection{Preparação do extrato de Noni}

A obtenção do extrato de Noni foi realizada a partir do fruto maduro previamente descascado, despolpado e as sementes foram retiradas. Em seguida, os frutos foram passados em uma peneira de 400 micras e centrifugado a $600 \times g$ durante seis minutos. Após a centrifugação, os sedimentos filamentosos foram removidos com auxílio de peneira, para, em seguida, se filtrar o extrato em copo coletor com uma peneira de 10 micras (NASCIMENTO et al., 2016).

\section{2 Óleo essencial de Melaleuca}

O extrato puro do óleo de melaleuca foi obtido em farmácia por manipulação na concentração 10\% (v/v).

\subsection{Cultura do fungo $C$. Albicans}

O meio Sabouraud Dextrose foi utilizado para o cultivo da levedura, que foi realizado em placas de Petri pela técnica de espalhamento. A cultura foi mantida em estufa por um período de 7 a 14 dias em temperatura de $28-30^{\circ} \mathrm{C}$.

\subsection{Ensaio do efeito antimicrobiano do extrato de Noni e do óleo essencial de Melaleuca sobre C. albicans}

Foram utilizados discos de papel de filtro de $6 \mathrm{~mm}$, umedecidos com extratos de Noni e óleo de melaleuca nas concentrações testadas: $40 \mathrm{mg} / \mathrm{mL}$ (Noni), $10 \%(\mathrm{v} / \mathrm{v})$ colocados sobre o meio de cultura sólido previamente inoculado em placas de Petri com os fungos.

Como controle positivo, foi realizado disco de papel impregnado com o antifúngico sintético Fluconazol ( $12 \mathrm{mg} / \mathrm{mL})$. Como controle negativo, foi utilizado o etanol de cereal $70 \%(\mathrm{v} / \mathrm{v})$. Todos os testes foram realizados em triplicata e os halos de inibição do crescimento foram medidos utilizando-se um paquímetro. Todos os experimentos foram realizados de forma asséptica em capela de fluxo laminar e em triplicata. Os testes foram realizados doze vezes em triplicata e os dados obtidos baseiam-se na média estatística dos halos de inibição observados.

Para isso, os dados obtidos foram tabulados no Software Graph Pad Prism e as medidas dos halos foram analisadas estatisticamente pelo teste One Way Anova. 


\section{RESULTADOS}

Os halos de inibição foram medidos com auxílio de um paquímetro e duas das placas analisadas podem ser vistas na figura 1.

Em todos os testes realizados, o óleo de melaleuca foi o que apresentou o maior halo de inibição, seguido pelo Fluconazol. Pode-se observar, de acordo com as médias calculadas dos halos apresentados, que o óleo de melaleuca apresentou maior potencial de inibição, quando comparado ao controle negativo e ao Noni ( $p \leq 0,0001)$, como pode ser visto no Figura 2. Nela, o óleo de melaleuca mostrou ser tão eficaz quanto o Fluconazol para inibir o crescimento da C.albicans in vitro, não havendo diferença estatística entre as duas amostras comparadas. Esse dado é relevante uma vez que o Fluconazol é um antifúngico muito utilizado nas clínicas médicas e, além dos efeitos colaterais, não tem tido muito sucesso no tratamento desse tipo de infecção. Isso porque, o tratamento é longo e os pacientes o abandonam antes da eliminação completa do fungo (CASTRO et al. 2016).

De modo similar, Santos e Casteluber (2020) observaram que o óleo essencial de melaleuca mostrou-se tão eficiente quando o Itraconazol para inibir o crescimento de Sporotrix schenckii nos ensaios in vitro. Carvalho et al. (2018), em sua pesquisa, mostraram a eficácia do óleo essencial de $M$. alternifolia contra Candida albicans, no qual foi observado que, na concentração de $10^{-1}$ e $10^{-2}$, o óleo essencial foi capaz de inibir $100 \%$ do crescimento fúngico.

A eficácia do óleo essencial de melaleuca também foi comprovada in vitro contra fungos fitopatogênicos como: Macrophomina phaseolina, Sclerotinia sclerotiorum e Alternaria alternata (MARTINS et al., 2011). Estudos de Cox et al. (2001) e Sudjana (2012) sugerem que a Melaleuca alternifolia é capaz de desnaturar proteínas, alterando assim as propriedades e funções desempenhadas pela parede celular, o que ocasiona perda de componentes intracelulares e apoptose celular.

De acordo com os dados observados na Figura 2, o Fluconazol e o óleo essencial de melaleuca apresentaram uma maior capacidade em inibir o crescimento de $C$.albicans, quando comparados ao extrato do Noni $(p<0,001)$. No entanto, o Noni apresentou capacidade de inibir o crescimento de C.albicans $(p<0,05)$, quando comparado ao controle negativo de álccol $70 \%(v / v)$. Mesmo a eficácia do Noni sendo menor do que a apresentada pelo Fluconazol para a inibição de C.albicans, a utilização do Noni contra a C.albicans mostrou-se favorável nos testes in vitro, já que halos de cerca de $10 \mathrm{~mm}$ de diâmetro puderam ser observados, quando o extrato de Noni foi verificado em placas. Os dados permitem sugerir que a utilização do Noni poderia ser uma alternativa para tratamento de C.albicans por populações que não tenham acesso à medicação ou aquelas que deixaram de tratar com o Fluconazol devido aos muito efeitos colaterais e à necessidade de utilizar esse medicamento por longos períodos. Novos estudos precisam ser feitos in vivo, a fim de comparar se os extratos aqui testados poderão desempenhar melhor efeito de inibição, quando comparados ao Fluconazol ou até mesmo associando o tratamento alternativo com o uso desse medicamento. Os estudos que apontam a utilização de plantas medicinais ou seus extratos são de suma importância, pois colaboram para difundir os saberes das propriedades terapêuticas das plantas e ampliar o conhecimento das potencialidades medicamentosas, impulsionando assim a utilização de fitoterápicos (STEFANELLO et al., 2018), principalmente por pessoas que não toleram os muitos efeitos adversos que podem ser causados pelo Fluconazol utilizado por longos períodos (CASTRO et al. 2016). 
Figura 1: Halos de inibição apresentados na análise das placas nos testes de difusão em ágar Mueller-Hinton. F - Fluconazol (controle positivo), M - Melaleuca, N -Noni, A-Álcoll 70\% (controle negativo).

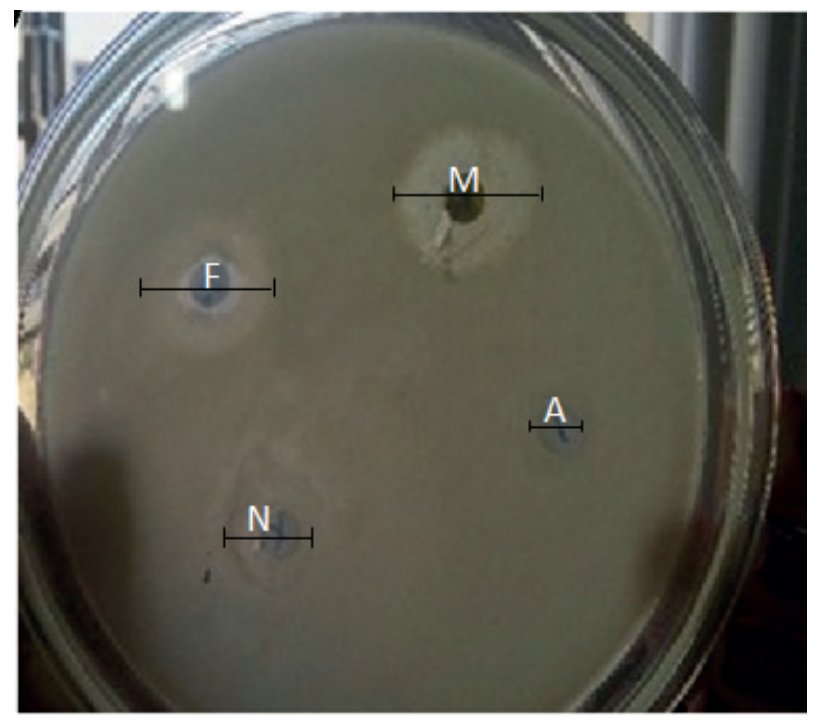

Fonte: autores

Figura 2: Eficácia do óleo de Melaleuca e do extrato de Noni como inibidores de C.albicans.

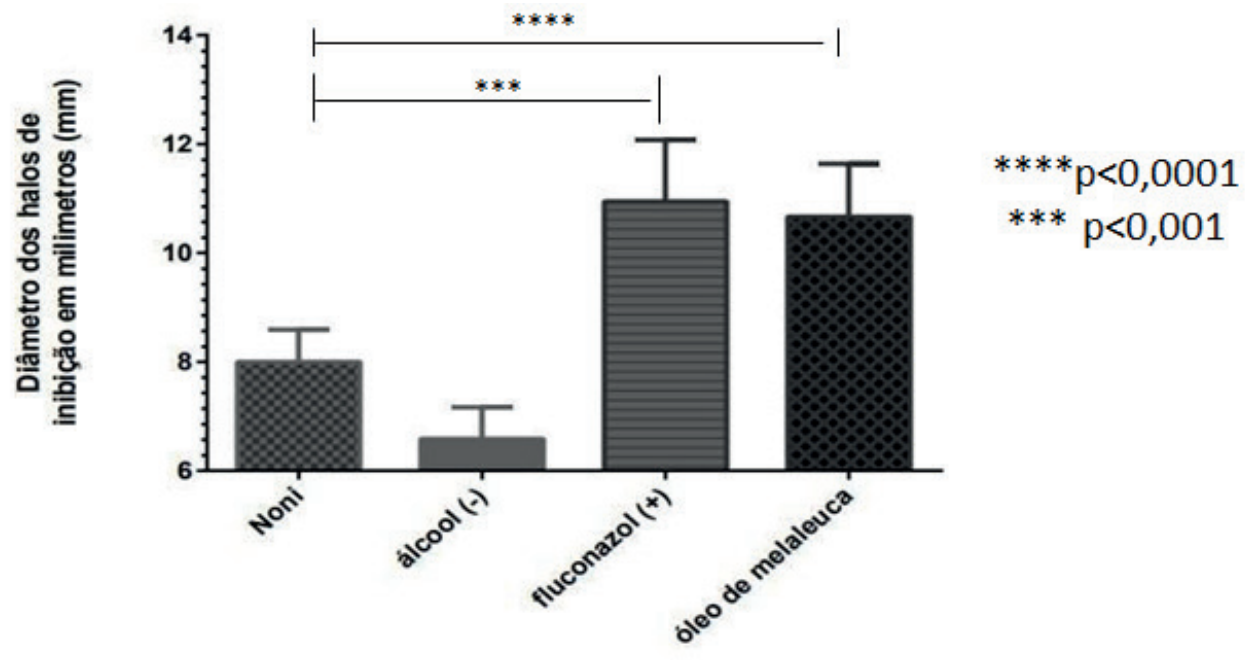

Fonte: autores

\section{CONCLUSÃO}

Os resultados obtidos demonstraram que o extrato de Noni e o óleo essencial de melaleuca foram capazes de inibir o crescimento da C.albicans. O óleo de melaleuca foi a solução teste que apresentou o maior potencial como inibidor do crescimento desse fungo, apresentando halos de inibição maiores do que os observados com o Fluconazol. Os dados obtidos neste estudo podem sugerir que o óleo de melaleuca poderia ser utilizado como solução tópica, sozinho ou somado ao Fluconazol, para auxiliar no tratamento de $C$. albicans. Apesar do extrato do Noni ter apresentado halos menores de inibição da C.albicans, quando comparados ao medicamento controle (Fluconazol) e ao óleo de melaleuca, ainda assim sua utilização como inibidor do crescimento desse fungo foi observada. Uma alternativa poderia 
ser a utilização do Noni na forma de pomada ou loção a fım de concentrar os compostos antimicrobianos presentes no extrato do fruto e desse modo, a aumentar sua capacidade em inibir o crescimento da C.albicans. $\mathrm{O}$ aumento da concentração dos fitoterápicos presentes no Noni poderiam induzir resposta semelhante ao Fluconazol, sendo que ainda é necessário considerar o fato do baixo custo de produção e facilidade de encontrar o fruto no país, o que justificaria essa abordagem. Os dados obtidos no presente estudo permitem sugerir que o Noni seja também utilizado para complementar o tratamento convencional, sendo necessários estudos in vivo para confirmar essa afirmação.

Além da vantagem de não precisar ser ingerido, esse extrato e o óleo essencial testados possuem baixo valor comercial, o que atenderia também as populações de baixa renda que têm dificuldades no acesso aos tratamentos médicos e aos medicamentos que são mais caros e usados por longo tempo até a cura. Desse modo, o óleo essencial aqui testado e o extrato do Noni poderiam ser utilizados como tratamentos alternativos contra as infecções por C.albicans.

\section{REFERÊNCIAS}

BARANI, K. et al. Anti-fungal activity of Morinda citrifolia (Noni) extracts against Candida albicans: An in vitro study. Indian Journal of Dental Research, v. 25, p. 188-190, 2014.

BOONANANTANASARN, K. et al. Morinda citrifolia leaves enhance osteogenic differentiation and mineralization of human periodontal ligament cells. Dental Materials Journal, v. 31, n. 5, p. 863-871, 2012.

CASTRO R.D.; LIMA E.O. Atividade antifúngica in vitro do óleo essencial de Eucalyptus globulus L. sobre Candida spp. Revista de Odontologia da UNESP, v. 39, n. 3, p. 179-184, 2010.

CASTRO, I.M.N. et al. Comparação da atividade de antifúngicos imidazólicos e triazólicos frente a Candida albicans. Revista Brasiliera de análises Clínicas, n. 48, v. 3, p. 216-222, 2016.

CORAZZA, Sonia. Aromocologia: uma ciências de muitos cheiros. 3. ed. São Paulo: Senac, 2004.

COX, S. D. et al. Interactions between components of the essential oil of Melaleuca alternifolia. Journal of Applied Microbiology, 91:492-497. 2001.

CRUZ, Maria Auxiliadora Gomes. Atividade inibitória de Morinda Citrifolia sobre Streptococcus mutans e Candida albicans. 2013. Dissertação (Mestrado em Biopatologia) - Universidade de Uberaba, Uberaba, 2013.

DUARTE, M. C. T. Atividade Antimicrobiana de Plantas Medicinais e Aromáticas Utilizadas no Brasil. Revista MultiCiência, n. 7, p. 1-16, 2006.

MELO, A.P.V. Fatores de virulência de Candida spp. obtidas de hemoculturas de pacientes com candidemia atendidas em hospitais terciários do nordeste do Brasil. (2016). Dissertação (Mestrado em Ciências Farmacêuticas) - Centro de Ciências da Saúde, Universidade Federal do Rio Grande do Norte, Natal, 2016.

FEIJÓ, A. M. et al. Plantas medicinais utilizadas por idosos com diagnóstico de Diabetes mellitus no tratamento dos sintomas da doença. Revista Brasileira de Plantas Medicinais, v. 14, n. 1, p. 50-56, 2012.

GUPTA, MAGABIR P.; SANTANA, ANA I. El fruto de Noni (Morinda citrifolia L). Revista de Fitoterapia, v. 12, n. 1, p. 45-52, 2012. 
LIMA, A. Caracterização química, avaliação da atividade antioxidante in vitro e in vivo e identificação dos compostos fenólicos presentes no pequi (Caryocar brasiliense Camb.). 2008. Tese (Doutorado em Ciência dos Alimentos) - Faculdade de Ciências Farmacêuticas, Universidade de São Paulo, São Paulo, 2008.

MARTINS, I. M. C. L. B. Avaliação da ação antifúngica de Citrus limon Linn frente a leveduras do gênero Candida. 2009. Tese Mestrado - Diagnóstico Bucal, Programa de Pós-Graduação em Odontologia, Universidade Federal da Paraíba, 2009.

MARTINS, J. A. S. et al. Avaliação do efeito do óleo de Melaleuca alternifolia sobre o crescimento micelial in vitro de fungos fitopatogênicos. Bioscience Journal, n. 1, v. 27, p. 49-51, 2010.

MOREIRA, Tatiana Maria de Souza. Estudo da composição química, citotoxicidade e alvos da atividade antifúngica de Melaleuca alternifolia Cheel (Myrtaceae) e de Plinia cauliforlia (Mart.) Kausel (Myrtaceae). 2010. Tese (Doutorado em Ciências Farmacêuticas) - Universidade Estadual Paulista, Faculdade de Ciências Farmacêuticas, Araraquara, 2010.

NELSON, S. C; ELEVITCH, C. R. Noni: the complete guide for consumers and growers. Permanent Agriculture Resources, Holualoa-Hawaii, 2006. 104p.

NETO, M. M et al. Candidíase Bucal: Revisão da Literatura. Saúde, Rio Grande do Sul, v. 31, n.1- 2, p. 16-26, 2005.

OLIVEIRA, A.C.M. et al. Emprego do óleo de Melaleuca alternifolia Cheel (Myrtaceae) na odontologia: perspectivas quanto à utilização como antimicrobiano alternativo às doenças infecciosas de origem bucal. Revista Brasileira de Plantas Medicinais - UNESP, v. 13, n. 4, p. 492-499, 2011.

PAWLUS, A. D.; KINGHORN, A. D. Review of the ethnobotany, chemistry, biological activity and safety of the botanical dietary supplement Morinda citrifolia (Noni). Journal of Pharmacy and Pharmacology, v. 59, n. 12, p. 1587-1609, 2007.

SANTANA, D. P. et al. Novas abordagens sobre os fatores de virulência da Candida albicans. Revista de Ciências Médicas e Biológicas, v. 12, n. 2, p. 229-233, 2013.

SANTOS, D. L. et al. Vista do Saberes tradicionais sobre plantas medicinais na conservação da biodiversidade amazônica. Unicamp. Disponível em: https://econtents.bc.unicamp.br/inpec/index. php/cef/article/view/9894/5291. Acesso em: 16 nov. 2020

SANTOS, J.R.E.; CASTELUBER, M.C.F. Citrus limon, Melaleuca alternifolia e Psidium guajava como inibidores naturais de Sporothrix schenckii. Revista UNINGÁ Review, v. 35, p. 1-19, 2020.

SCHULZ, V.; HÄNSEL, R.; TYLER, V.E. Medicinal plants, phytomedicines, and phytotherapy. In: SCHULZ, V. Rational phytotherapy: a physician's guide to herbal medicine. 4.ed. New York, Berlin: Springer, 2001. cap. 1, p. 1-39.

SILVA, C.R.M, NAVES, M.M.V. Suplementação de vitaminas na prevenção de câncer. Nutrire, São Paulo, v. 14, n. 2, p. 135-43, 2001.

STEFANELLO, S. et al. Levantamento do uso de plantas medicinais na Universidade Federal do Paraná, Palotina -PR, Brasil. Revista Extensão em Foco, n. 15, p. 15-27. 2018 
SUDJANA, A. N. et al. Candida albicans adhesion to human epithelial cells and polystryene and formation of biofilm is reduced by-inhibitory Melaleuca alternifolia (tree tee) essential oil. Medical Mycology, v. 50, p. 863-870, 2012. 